\title{
Exploring the Image and Direction of Filial Piety Education in Modern Society
}

\author{
Byung-Chul Lee ${ }^{1}$ \\ ${ }^{1}$ Professor, 46958 College of General Education, Silla University, Gwaebeop-dong, Sasang-gu, \\ Busan, Korea, labcla6@silla.ac.kr
}

\begin{abstract}
This paper explored the aspect and teaching of filial duty education in modern society based on Mothers Heart by Yangju Dong, Morals textbook of middle schools, Livelihood and Ethics of high schools, and the Myeongnyun textbook of Hyangyo Foundation in Gyeonggi-do Province. Overall, the textbooks of middle and high schools not only had the small quantity for filial duty but also covered the with its general meaning. On the other hand, the Myeongnyun textbook, which served the purpose of community education level, made us understand deeply and approachable. Particularly, the textbooks of middle and high schools had with content-shortages and could be misunderstood in the aspects of essential approach of filial duty education. Furthermore, this study suggested the school education for the direction and proliferation of filial duty education and its contents in the social-educational dimension. In addition, this paper examined the discussion related to filial duty. Particularly, the essence of filial duty education should be accompanied with the extensive approach and discussion based on "the concept and origin of filial duty, the necessity and values of filial duty, the filial duty as a traditional thought, our ancestors filial duty practices, how filial duty influences an individual life, how filial duty influences human relationship, the practices and task of filial duty at home, how filial duty influences a society, country, humanity, the historical effort to succeed filial duty, and the historical perspective and evaluation for filial duty." The non-practical filial duty education could not confer its values. Furthermore, it is needed to promote the superior practical education in relation to various academic societies, social education institutions and lifelong education institutions. Filial duty is neither the custom from the past nor the fixed relics. It is the traditional thought and culture as Korean people's spiritual heritage.
\end{abstract}

Keywords: Direction of Filial Duty Education, Reciprocal Problems, The Root of Bujajahyo, Filial Duty Thought, School Education, Personality Education

\section{Introduction}

In the modern society, there exists an important task for the developing succession of filial piety, that is, the necessity of filial piety education and the approaches to its relevant contents. This should be realized to meet the demands of the filial piety spirit in the current era. It is necessary to secure the mottos from filial piety education for the people's traditional succession and the spiritual basis of the modern society in moral culture.

For the filial son, it is imperative that he serve his parents devotedly. This is related to the statement we can't help knowing our parents' age because we are delighted by our parents's longevity and also afraid of their limited life expectancy. As we are all mortal, we cannot have enough time to serve our parents devotedly. Consequently, a filial son must ensure to spend a day to support his parents.

Received: October 08, 2020; 1st Review Result: November 25, 2020; 2nd Review Result: January 14, 2021 Accepted: February 26, 2021 
Our society has passed through breathless changes without looking back to our past. After the Korean War, we have overlooked our traditional culture and thought obscured by the economic progress of industrialization. Overflowing individualism and excessive seeking for materialism make us ignore the minimum sense of morality and ethics. As the result-orientedness, dead-end, and winner-takes-all system manifest, the social sentiment by the fair means or foul has been growing in pursuit of their ends by diminishing concession and compromise.

Furthermore, in terms of the recent discussions, the filial piety is considered a spiritual heritage, thus, approaches for practical issues are vigorously attempted[1-5]. Various studies focused on childrencentered support for their parents based on the reasonable family relationship rather than authoritarian filial piety education as well as modern implementation for filial piety and perspectives for family ethics[6]. The traditionality of filial piety on fundamental pursuit for human decency indicates publicness for social integration binding together traditional society and emphasizes the function of existing values of the modern society[7].

The recently emerging filial piety contract and prevention of undutiful child is an aspect of a rapidly changing society. While filial piety contract intends to prevent undutifulness, the prevention law for undutifulness encompasses the restriction of post-control aspects[8]. Before, we have tried to teach and encourage filial piety behavior and have regarded its act as a model of example of human act as we have considered filial piety as the best virtue.

The legislation on undutiful child indicates that the inheritance of a child can be confiscated if he/she do not serve his/her parents faithfully even without engaging in a contract. According to the Daily Korea survey on 2016 participated by 567 adults over 19, among those is their 50 s, $87 \%$ agree on the necessity of filial piety contract and $79.1 \%$ on the legislation on undutiful child. On the other hand, among those in their $20 \mathrm{~s}, 64.7 \%$ reveal their sympathy for the necessity of filial piety contract and $40.2 \%$ for the legislation on undutiful child.

Although filial piety is enacted and enforced by the law, it is feared that its mind and spirit will be debased. However, it has also been clamoring for making filial duty compulsory. "The law on filial piety behavior encouragement and support(2008.08.04.)" is enacted and the implementation of "act on the promotion of personality education(2015.07.21.) is thought to be a movement of social requirement and deficiency fulfillment by including filial piety as an essential virtue and value of personality education.

As filial piety education is the duty of humanity, it can be the essence of personality education for the youth. Accordingly, this discussion examines the features of filial piety education in the before modern society and suggests the direction for expanding filial piety education in conclusion. It will investigate the possessing parts in the aspects of education, the problems which should be corrected to easily understand filial piety based on middle and high school textbooks. This discussion not only provides the modern meaningful implementation but also parallels with the domains of social integration and the recovery of family ethics as a social elements of practice. It is not the filial piety as the classical remains confined by our tradition and thought. It will be the supplement of filial piety education in the filial piety awareness of modern society which can be realized in our body and soul.

\section{Development of Filial Piety Education in Modern Society}

Human beings have identified themselves through their relationships with others. One's right perception determines his or her own life. Through relationship with others, the existence of "I" is revealed. There is a reason that we need to pay attention to the recognition of "you". Initially, a parent's recognition determines ones life. Consequently, filial piety can be a socially practice element as it indicates the relationship between recognition for parents and one's existence.

Earlier, Yulgok said that as God look into me and filial piety is the top of all activities, Tao which controls household affairs takes filial piety and reverence first. He thinks of the basis of all the acts as 
filial piety in the beginning of human relationship. Human relationship starts from parents and their children and is extended into other beings' recognition.

The recognition for parents is the recognition for our neighborhood and the positive recognition for parents functions as the positive recognition for other beings. This is the reason why we regard filial piety as the source of all virtues. Human beings' right recognition and act stem from filial piety. As filial piety is a guideline for a humanlike life, the recognition for parents operates on the base of humanlike recognition and act.

The implementation of Parents' Day is an enactment every 8th of May to appreciate parent's grace and raise awareness for respecting the elderly people. In 1956, the Mother's Day and Father's Day celebrations were commemorated separately as a way to comfort parents after the Korean War and as the children's filian duty. On March 30, 1973, the events were later assigned as Parents' Day.

On this day, sons and daughters from households across the country have given carnations or presents for their parents and grandparents or sent their parents on a trip. At the ceremony from all over the country, the prizes for devoted sons and daughters were awarded. Also, the feasts or privileges of industrial inspection were given. In addition, the week for respecting the elderly people was celebrated, where those in the nursing homes and senior community centers were visited. However, the week for respecting the elderly people was regrettably abolished in 1997.

From One Hundred Years of Western Music in Korea, "Forgetting all the pain of giving birth, Trying day and night to grow me well. Laying me on a good seat, not a bad one, Till her hands and feet wear out, she aches her bone for me. Under the sky, what can be wide, Mother's sacrifice is endless. When I was young, she held, carried \& soothed me, and, When I was tall, she waited for me leaning against the door. Thinking of her child that may be sick or wrong, Her pretty forehead was full of wrinkles. On the ground, what can be high, Mother's sincerity is. All kinds of wishes for people's mind but only one wishes for mother's heart. There is nothing holy like her wishes for their children as she gladly gives her own fleshes and bones for them. Mother's love is extremely devoted."

The song lyrics of Mother's Heart make us understand favor for our parents and respect for the elderly people. This song lyrics were jointly composed by Yang, Ju Dong and Lee, Heung Ryul. Since Mother's Day was enacted in 1956 and changed into Parents' Day in 1973, this song has still been sung by many people, impressing a lot in education fields and other places.

As it is composed of three-quarter time, this song has a unique format of traditional rules of versification like Goryeo songs. Namely, this song has the general rules of versification of 7.5 along with the basic rules of versification of 3.3 and 3.4. It consists of a total 217 words and its expression takes a structure of confrontation with antithesis and contrast, including first verse with 73 words, the second one with 71 words, and the third verse with 73 words.

The essence of the first verse is Mother's sacrifice, while the second one is Mother's sincerity, and third one is Mother's love. Perhaps, the climax of this song is believed to be the passage of "What else is broader than Mother's Heart under the sky? What else is higher than Mother's Heart over the land? What else is more divine than Mother's Heart?"

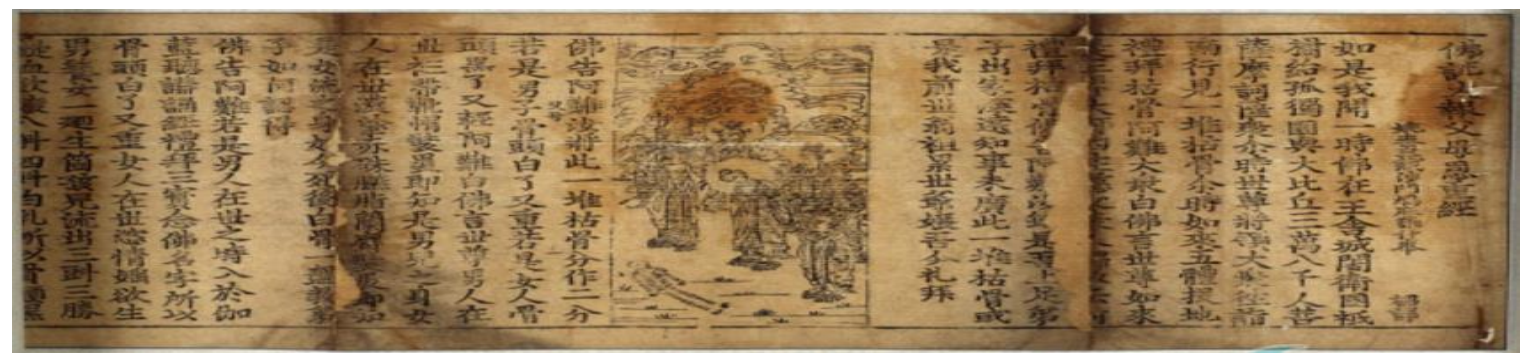

[Fig. 1] BurSeorDaeBo Bumoeunjunggyeong Text (The Academy of Korean Studies) 

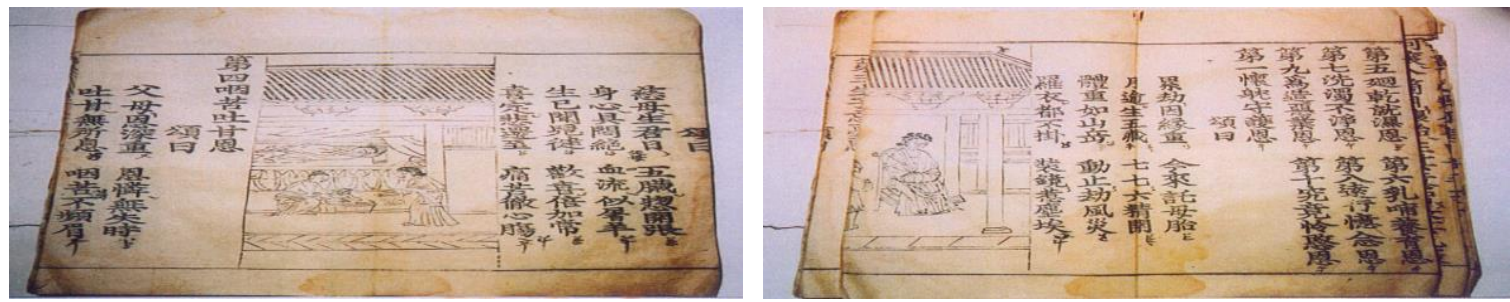

[Fig. 2] Bumoeunjunggyeong Text GeSong (The Academy of Korean Studies)

The song lyrics of Mother's Heart by Yang, Ju Dong remind us of the filial piety episode in Myungshimbogam, the Yoa episode in The Classic Anthology defined by Confucius, Samogok in Goryeo Gayo. Above all, it becomes evident that the song lyrics were immersed most to the contents of Bumoeunjunggyeong[9]. In particular, we can feel 'Mother's 10 beneficences' throughout the song lyrics. However, we do not live with deeply engraving Mother's Heart these days. Exactly speaking, there is no denying that contemporary men's lives grow apart from filial piety.

The problems of undutifulness are in line with the stream of times beyond personal ethics. There is a seriousness of situation because the problems are the spiritual manner's domains for people's lives and society, that is, the problems of social structural aspects accompanied with changes of morals and paradigm[10].

1. Children should have filial piety to return their parents' love. The children who do not forget their parents' affection respect them and will have filial piety materially[11].

2. However, filial piety is not the elders' love for the young so it can be practiced by steady efforts [11].

3. Children do not forget their parents' love and try to do their best to make them feel comfortable[11].

4. Children should practice filial piety with thankful mind for their parents. However, it is not appropriate that filial piety is enforced to the unilateral duty for their children. The practice of true filial piety should be based on a reciprocal principle of Bujajahyo where parents gave an affection, so children pay the price[12].

5. When children do filial piety, what kind of mindness is needed? True filial piety should come from feeling reverence for our parents. We do not perform filial piety materially. True filial piety should be based on gratitude, benevolent, and love for our parents together with a practice of sunny spot respecting parents' will[12].

6. Moreover, this filial piety spirit should be extended to the neighborhood, community, country, and all mankind and make a base of neighborly love, reverence for the elderly, volunteer work, etc[12].

7. Filial piety the basis of all acts. This means that the beginning of all etiquette starts from filial piety. Based on Myeongnyun textbook, "From the time when I was conceived in my mother's womb or long before my mother and father cherishes and loves me with all their hearts. If this is our parents' natural order for me, my order is to give my love to them. That is filial piety. Ultimately, filial piety is a loving expression for my parents[...]" Before, filial piety for the elderly means coming home, which can be extended to Gyungjang thought. When filial piety spirit is extended to country, it becomes patriotism [13].

From individual changes, social changes begin. Education changes both the individual and the society. Individual changes are possible in a domain of the society where one belongs to. Therefore, students' life is formed in the social space of school which they belong to, and their changes are accomplished through education. This is the reason why we should be interested in the contents and methods of education.

Chapters one to seven are the contents of the textbooks on filial piety education. Chapters one to three are textbooks in middle school, four to six are everyday ethics in high schools, seven contains the Myeongnyun textbook in the Confucian schools of Gyeonggi-do. The key words on chapters one to 
three are love and affection, reverence and support, and the practice by steady efforts (the implementation of physical aspects). Chapter three has a clause that children make their parents feel comfortable (the implementation of spiritual aspects). In general, most of the middle and hight school textbooks, which have poor contents and small quantity of filial piety, end up in describing the meaning of filial piety.

Chapters four to six make no difference. As textbook four is a gratitude for parents' devotion and practical principle of filial piety, it suggests a reciprocal principle of Bujajahyo. Chapter five is about a heart of reverence, material support, practice of sunny spot, gratitude and repayment for parents' sacrifice, etc. Chapter six states that we should extend this filial piety spirit into the neighborhood, community, country, and humanity. In doing so, we should practice neighborly love, reverence for the elderly, volunteer work, etc. Consequently, chapters four to six are also limited because it contains an affective approach for descriptions, contents, and quantities.

Chapter seven are used by 30 Confucian schools of Gyeonggi-do. It stated that "the basis of human acts, courtesy origin, parents' affection is a natural order of humanity, filial piety thought for the elderly, Gyungjang thought, loyalty thought, etc.”.

The Myeongnyun texbooks have social education purposes. The fourth and fifth chapters attempts various approaches on filial piety. The entire contents increase considering the third and sixth chapters describing "my family" and "my neighborhood society" in terms of an extension of filial piety. The contents are as shown in the table below.

[Table 1] Myeongnyun Textbook

\begin{tabular}{|l|l|}
\hline Contents & The features of filial piety through Myeongnyun textbook in confucian schools of Gyeonggi-do. \\
\hline & $\begin{array}{l}\text { 1. Keeping healthy his or her body. } \\
\text { 2. The spirit and mind for respecting parents. } \\
\text { 3. Making parents comfortable mentally. } \\
\text { The contents of } \\
\text { suggested filial } \\
\text { piety. }\end{array}$ \\
$\begin{array}{l}\text { 4. Taking good care of parents and respecting them with filial piety. } \\
\text { 5. Support, politeness and gentleness for serving parents materially. }\end{array}$ \\
$\begin{array}{l}\text { 6. Following parents wishes by not opposing their wishes. } \\
\text { 7. Respecting parents and ancestors by holding a memorial service. } \\
\text { 9. Children brighten and reveal their parents in a position of honor. }\end{array}$ \\
\hline
\end{tabular}

Filial piety is shortly mentioned as the contents of desirable family in small lesson units in ethics textbooks of middle schools. They describe children's love for their parents in the perspective of a dictionary. Contents are systematic and is based on concrete experiences. Diversification of textbooks can be developed into a diversification of experiences. The course composed of simple contents that deprive students of their opportunities and does not make students feel the importance of filial piety.

It is difficult to "pay attention to their parents and realize children's duty" and to motivate students to practice filial piety behavior if they only study through the contents of the textbooks.

This circumstance is no different to high school living and ethics textbooks. In small lesson units of family values and ethics lesson units between parents and their children, filial piety is shortly mentioned. In addition to lack of contents of textbooks, the process of description of chapter four on filial piety may leave some doubts for students' understanding.

Though the narrator's intention is sufficiently known, the proposition may lead to a mistaken impression for filial piety. For example, the third statement in chapter four indicates the right practices of filial piety and "should be based on reciprocal principle of Bujajahyo." Bujajahyo meansthe virtues of the parents and their children, wherein parents are affection and their children are filial piety, respectively. 
This statement defines filial piety as a proposition by using the word of principle and basis. Reciprocality means exchanging special conveniences, profits and benefits for each other. Speaking conclusively, it may implant the mistaken meaning of filial piety which means "you give me, so do I" for students. If the natural order of parenthood indicates affection, then so it is for the children towards their parents. It is said that the revelation of filial piety is the basis of moral laws, passerbys, and all the decorum. The with regard to this, the contents are as follows.

As we learn and seek something of worth, filial piety becomes the basis of the activity. Confucius says "filial piety as the basis of virtue springs from the teachings. He says "teaching affections for their people is nothing less than filial piety." He says "filial piety is a psalm of heaven." He says "as it is difficult for human beings to give offense to the will of God, a person's behavior is not as big as filial piety." He says "as Samchun exists belonging to the five punishments, there is a no more sin than undutifulness"

This statement suggests a correct teaching on filial piety. The relationship between parents and their children is not reciprocal but proper gratitudes should be the basis of moral laws of love and beneficence for the parents. It is our share to teach our children the right gratitude as part of the children's duty. Therefore, the expression of reciprocal principl should be corrected and supplemented.

\section{Filial Piety's Approach and its Seeking for Direction}

The following statement of a crow's habit is written in Bencao Gangmu published by Si Jin Lee's late years. Sixty days after hatching out baby crows, a mother crow raises them by earnestly feeding them. However, when baby crows are fully grown, they feed the exhausted mother crow. Therefore, a crow is called Banpojo, Jao and Banpo originated from the habit to feed the mother crow by baby crows. This means heartwarming filial behavior, thus, Banpojihyo means being extremely devoted to his or her parents.

The practice of filial piety as human beings is a matter of course and domestic happiness comes from filial piety. Seeing mere crows act like this, human beings should follow those crows' behaviors. Human beings must do filial piety. We should try our best though there exists insufficiencies.

Filial piety behavior makes people modest and have right acts. Here comes the necessity and values of filial piety education. As it is humanity's duty, filial piety education can be an essential prerequisite. This can be found in Naepyeon of Sohakjipju[14].

A devoted son, who feels a deep love for his parents, necessarily has a gentle energy. A person, who has a gentle energy, necessarily has a happy look and a person, who has a happy look, necessarily has a gentle look. A devoted son must support his elderly parents with all his heart by making his parents' minds pleasant, yielding to his parents, making their eyes and ears pleasant, making their beds and shelters comfortable, serving them with foods.

Filial piety is an integral part of life which is not treated as a simple duty. As it is not everything in terms of describing the contents of their children's duty, top priority of filial piety education should try to internalize filial piety. Direction and discussion of educational approaches for filial piety is currently needed.

The contents of "filial piety's concept and origin, filial piety's necessity and values, filial piety as our traditional thought, filial piety behavior of our ancestors, how filial piety affects personal life, how filial piety affects interrelaionship, filial piety's practice and task at home, how filial piety affects society, country, humanity, historical effort for succeeding filial piety, historical perspective and evaluation for filial piety, etc." should be reflected. Particularly, the basis of filial piety education should be accompanied with broad accesses and understandings centering around the the contents as shown below: 
[Table 2] The Direction of Filial Piety in Educational Aspects

\begin{tabular}{|c|c|}
\hline Contents $\quad$ Text & The direction of filial piety in educational aspects and the embodiment of accessible contents. \\
\hline $\begin{array}{l}\text { The contents of } \\
\text { suggestion. }\end{array}$ & $\begin{array}{l}\text { 1. The origin and concept of filial piety. } \\
\text { 2. The necessity and value of filial piety. } \\
\text { 3. The succession of filial piety and historical endeavor. } \\
\text { 4. The historical perspective and evaluation for filial piety. } \\
\text { 5. The filial piety spirit as traditional thoughts. } \\
\text { 6. The good examples of filial behavior from ancestors. } \\
\text { 7. How filial piety affects personal life. } \\
\text { 8. How filial piety affects human relationship. } \\
\text { 9. The practice and tasks for filial piety at home } \\
\text { 10. The problems of filial piety in social, national, universal aspects. }\end{array}$ \\
\hline
\end{tabular}

In addition, regarding the historical perspectives and evaluations for filial piety, how filial piety affects our life as a positive effect and also a negative effect caused by distorted perceptions for filial piety should be considered from many different perspectives. This I believe that this series of directions attract public concerns and can lead their various participations. Filial piety is not a mere traditional relic from the past but life itself of ethnic group.

Consequently, it is our spiritual inheritance and traditional culture and thought succeeding from our lives across time and space. This process of discussion is believed to be an answer of educational dimensions which can contribute to the current cultural creation, not as a relic from the past, in a dimension of the tradition and succession of filial piety thought.

Filial piety is humanity which is the concept incorporating family, social, and national order as well as private cultivation. As its basis is benevolence and virtue, filial piety needs educational establishment as a way of the five constant virtues. The extended virtue through filial piety's basic idea is realized by harmony in the family, faith in the community, ethics for serving elders, tenderness for juniors, loyalty for serving his or her country, patriotism for ruling his or her people[15].

[Table 3] The applicable Examples

\begin{tabular}{|l|l|}
\hline Contents & Text \\
\hline \multirow{2}{*}{ examples } & $\begin{array}{l}\text { 1. Meeting with filial daughter-in-law, filial son, filial daughter, filial grandchildren and Special } \\
\text { Lecture Preparation. }\end{array}$ \\
$\begin{array}{l}\text { 2. Practicing filial piety every day. } \\
\text { 3. Writing the record of filial piety practiced by themselves. } \\
\text { 4. Making the lists of practicable filial piety. } \\
\text { 5. Making records of grateful parents' love. }\end{array}$ \\
\hline
\end{tabular}

At first, it may be unfamiliar and burdensome for students. However, it is not so difficult for middle and high school students to be taught with humanistic education and assign special hours for filial piety education in organizing curriculum. In addition, it is persuasive to provide the suitable and concrete materials for presenting filial piety award in societies and middle and high schools. Also, it can be contributed to the aspects of repairing the relations with parents or seniors and different generations.

First, it is the relationship between industrialization and filial piety. Expanding wealth by developing industry is an important matter of modern people. The matter of serving his or her parents faithfully and raising their children is not accomplished in affluent materials though it is not accomplished in poverty[...] Filial piety thought seeks for a person's social and economic accomplishment to fulfill 
responsibility for his or her family by reprimanding escapism, incapacity and indolence rather than shrinking economic activity. Consequently, when it come to expand and manage wealthy by developing industry, the spirit of filial piety can motivate economic activity. Second, it is the relationship between democratization and filial piety[...] The human character of self-discipline and love for others must be honorable of all time. Real freedom should come from sincere self through self-discipline and real equality depends on the personality which doesn't turn away from the sufferings of others. Good community starts from the communication depending on real freedom and equality. In addition, healthy communication starts from real self rather than selfishness and deception overlooking disadvantages of others. The sincerity reaching for an authentic self and the pure emotion and philanthropy deriving from it are inherent in loyalty and filial piety, which is able to make the freedom of democracy more mature[16].

Examining the Myeongnyun textbook in confucian schools of Gyeonggi-do[13] and Moo Hyun Kim[15], Jae Cheon Jang[16] books, it can be possible to read the suggestiveness of extended concept of filial piety and its meaning. Stating the concept of filial piety in Myeongnyun textbook, the nine implementation contents of filial behavior are suggested.

It includes filial piety as safety(keeping his or her body safe), as reverence(mind and heart for respecting their parents), as Yangji(making their parents comfortable mentally), as Sibong(Serving their parents well and loving for them), as obedience(yielding to their parents), as expostulation(giving advice for the incorrect or wrong things), as service(holding a memorial service for their parents and ancestors), and as Hyunchin(succeeding in life and then brightening and revealing their parents)[13].

Discussing filial piety's basic ideas, Kim, Moon Hyun maintains that the root of filial piety is indivisibly related to the five constant virtues. In other words, filial piety based on humanity can be extended into the ruling ideals of home, society, nation as well as individuals. Consequently, he points out that the educational establishment of filial piety is urgently needed as ethical consciousness based on the virtues of "benevolence, loyalty, affection" is expanding.

For a discussion of "filial piety thought and filial piety education's importance," Jang, Jaecheon investigates some extraordinary aspects of 'industrialization and democracy' and relationship with filial piety through filial piety education as human education in chapter four. In short, it is said that the spirit of filial piety most motivates practical and active economic activity among all moral concepts.

Moreover, a harmonious family with parents and their children is completed by rejecting immoral economic activity and exerting humanity duty of faithfulness and hardworking. As it is not a filial piety behavior to blindly follow their parents' order deviated from humanity duty, real filial piety should not be against democratic principles. Filial piety behavior is not an obligation by external coercion or criterion but can be realized by each person's sentiment and independent emotion. It is emphasized that freedom and equality of character in all restraint are not contrary to the concepts of filial piety.

Like Confucius's statement, filial piety provide reasonable evidence for ethical standard of human beings if the origin filial piety can be found in humanity. Filial piety is the best way to practice humanity. Through this, human dignity is protected and joined by the basic concept of democracy which gives top priority to human dignity. In this respect, we can see that filial piety is a necessary virtue to provide an ethical principle and give an affective motive for action.

The human relationship starts from parents and their children. Parents affection and their childrens filial piety can be doubled in strength between their vigorous relationship. Educational and social concern for filial piety can provide the beginning of formation of a relationship for a community and its members. It is urgently needed to have more active concern of filial piety and social exertion for realizing filial behavior in a modern society. Considering the necessity and importance on filial piety education, some approaches are suggested related to filial piety education as follows.

First, we should consider and teach what as filial piety and why we should practice it by establishing the origin and spirit of filial piety[17]. In other words, approach for filial piety can be established by 
providing the various perspectives and implementation method of filial piety including themselves and others, filial piety's function and role in communities.

Second, filial piety education cannot be separated by reality. It should be concentrated to improve motivation and intent to act for practicing filial piety education at home and in social life. Filial piety education without practicing is worthless.

Third, the regular courses at schools should be planned in terms of education of humanism in filial piety education programme. Considering education of humanism as a basis of ethical consciousness as well as filial piety education is marginalized, more broad-minded educational discernment and thoughtfulness is needed. Though it can be regarded as theoretical, human beings lack of senses of morality and ethics should not be overlooked as their high education level may lead to side effects to our society.

Fourth, the subjects for education should be extended. It is needed to raise the securement of subjects for education and public concerns in various fields in society from primary and secondary school children nationwide to college students and the general public. It is filial piety to become the virtues and spiritual heritage by all the children in the world.

Fifth, the expertise of filial piety educational institutions should be promoted by organizing and encouraging the established filial piety educational institutions. In particular, it is needed to extend the specialized organizations in conjunction with various filial piety related academic societies, social education institutions, and life-long educational institutions in order to provide high-quality practical education.

Filial piety education should not be limited by the special people or subjects. In a modern society of rapid period of trend, the undesirable changes should be corrected and supplemented. The indifference and negligence to reality lead to the collapse of mankind and abandonment of life. In addition, this will lead to chaotic value order so that we will not be able to sustain a living worthy of human dignity. Filial piety education is an endless process and filial behavior is a basis for human dignity. The thought and sprit of filial piety should be internalized and realized without interruption and distortion of filial piety virtues in respect of society, country, and humanity.

\section{Conclusion}

When humans were born, the first people they see are their parents. We do not have an authority to choose our own parents but the recognition we give them decides our lives. The meaning of filial piety becomes a recognition of relationship, namely, a social practice element which goes toward the parents and perceives their existence. This is a ground for children to keep in mind the recognition of their parents. It becomes evident that filial piety is the basis of all our actions as the starting point of human relationship.

Chapter one discusses the image and lesson of filial piety education in modern society based on a morals textbook in middle schools, an everyday ethics in high schools, the Myeongnyun textbook in confucian schools of Gyeonggi-do, as well as a song Mother's Heart by Yang, Ju Dong and Lee, Heung Ryul.

A person's change leads to society's change. Education serves as a power source which changes both a person and society. It is necessarily important to have the contents and methods in this level of education. In general, most of the middle and hight school textbooks, which have poor contents and small quantity of filial piety, end up in describing the meaning of filial piety. On the contrary, the Myeongnyun textbook has broad understandings and approaches for filial piety, keeping pace with the purpose of social education.

In particular, most of the middle and hight school textbooks have problems on their poor contents and lead to the vehement misunderstandings for students. "However, it is not desirable to enforce filial piety 
as children's unilateral duty. The practice of true filial piety should be based on the reciprocal principle between parents and children."

Their relationship is not a reciprocal principle where parents gave an affection, so children pay the price. No matter how big or small the affection is, it is a gratitude for parents underlying human morality for their love and favor for conceiving and raising their children. It is a share for us to teach our children rightly as the gratitude is the descendents of human beings. Nevertheless, this reference defines and responds filial piety along with the word "reciprocal" adding up the usage of the word "principle" and "basis." Like this, the process of description for filial piety in high schools textbooks needs to be modified and supplemented. In addition, the improvement is necessary as it may leave room for argument in the academic world.

Chapter two suggests the school education for filial piety's direction and expansion and its contents in a social and educational dimension. In addition, Chapter two investigates a related discussion for filial piety. In particular, the basis of filial piety education should be accompanied by the broad approach and understanding on the basis of "the concept and origin of filial piety, the necessity and value of filial piety, the piety as a traditional thought, our ancestors' filial behavior, how filial piety affects a personal life, how filial piety influences human relationship, the practice and task of filial piety at home, how filial piety influences society, country, human beings, the historical effort for the succession of filial piety, the historical perspective and evaluation of filial piety, etc." The filial piety education without practice cannot place its values.

This discussion not only provides the modern meaningful implementation but also parallels with the domains of social integration and the recovery of family ethics as a social elements of practice. Furthermore, it is needed to plan a quality education in relation to various academic societies, adult educational institutions, and lifelong education institutions. As filial piety is a method of human morality, it can be the essence of an education of humanism. Filial piety is neither a custom derived from the past nor a fixed relic. It is a traditional idea and culture as the Korean people's heritage. Parents' affection and children's filial behavior increase in a healthy relationship.

In this respect, the approaching problem and direction exploration of filial piety education in Chapter three are urgently needed in our society. The educational and social attention for a filial piety is as good as a nourishment for healthy relationship between a community and its members. Consequently, it is a top priority to draw an investment and public involvement for a sustainable filial piety education beyond a short-term event planning in order not to get an unkind treatment in modern society.

\section{References}

[1] Ik Soo Kim, A Theory on the Innovation of Education in Korea - Focuses on the Education of Ethics, Korean Thought and Culture, (2015), Vol.79, pp.337-367.

[2] Byung Chul Lee, The Implementation and Tradition of the Meaning of Thought of Filial Piety, Korean Thought and Culture, (2018), Vol.95, pp.259-284.

[3 Kyu-jin Ham, Chi Chun Ho, Shin Chang Ho, Lim Hong Tae, A Study On Possible Utility of Korean Traditional Thoughts and Educational Practice In Contemporary Moral Education, Journal of Korean Philosophical History, (2016), Vol.50, pp.363-389, DOI : 10.35504/kph.2016..50.012

[4] Shin Hyun Ka, Jung Joo Kim, Jin Ah Park, A Study to Identify Modern Concept of Hyo and learning Contents of Hyo Culture Education, The Korea Educational Review, (2018), Vol. 24, No.3, pp.191-211.

[5] Jong Doo Kim, Eun Sook Seo, Gyun Yeol Park, The Modern Significance of Hyo and Its Implication to Family Ethics, KOREA ASSOCIATION OF NATIONAL THOUGHT, (2019), Vol.13, No.1, pp.149-193.

[6] Jin Gu Jeong, Dong Ho Lim, A Study on Korean Traditional Ideology of Filial Duty and Parent Support, Asia Pacific 
Journal of Multimedia services convergent with Art, Humanities and Sociology, (2017), Vol.7, No.5, pp.721-730, DOI : 10.35873/ajmahs.2017.7.5.066

[7] Baeg Hee Kim, On Public nature in Ethics of Filial Piety, Studies in Philosophy East-West, (2016), No.80, pp.77-96, DOI : $10.15841 /$ kspew..80.201606.77

[8] Kyung Min Eom, A Thought on the Legal Guarantee and Law of Filial Behavior, Youth and Culture of Filial Piety, (2018), Vol.32, pp.195-219, 10.31036/jyfpc.32.8

[9] Ezra Pound, The Classic Anthology Defined by Confucius, Translated by Hak Joo Kim, Myeongmoondang, (2002)

[10] Hyoung Yong Kwon, Research on The Actual Condition of Youth Happiness and Related Variables, Asia-pacific Journal of Convergent Research Interchange, (2019), Vol.5, No.3, pp.179-188.

[11] Soon Yong Buyn, Moral Textbook(Middle School), Cheonjaegyoyug, (2018)

[12] Seong Min Jo, Life and Ethics(High School), Bisanggyoyug, (2017)

[13] Myeongnyun textbook 2nd Ed, Gyeonggi Hyanggyo Foundation, (2009)

[14] The Oriental Classical New Book, Translated by Il bong Park, Yookmoonsa, (2000), Vol.8.

[15] Moo Hyun Kim, Filial Pietry in Oritental Classics, Hyo Inseong Education Promotion Agency Attached Institution by Korea Institute of Hyo Culture, (2016)

[16] Jae Cheon Chang, Historical Importance of Filial Piety Thought and Filial Piety Education, Youth and Culture of Filial Piety, (2015), Vol.25, pp.217-235.

[17] Bong Hwan Ji, An Analysis on the Filial Piety Education of Middle and High School, Youth and Culture of Filial Piety, (2014), Vol.23, pp.169-191. 